\title{
Capacidade de Eichhornia azurea (Swartz) Kunth de depurar água contaminada por coliformes termotolerantes
}

The ability of Eichhornia azurea (Swartz) Kunth to clean water contaminated by thermotolerant coliforms

\author{
T. L. Silva ${ }^{1}$; J. L. Fortuna ${ }^{2 *}$ \\ ${ }^{l}$ Departamento de Educação, Curso de Ciências Biológicas, Universidade do Estado da Bahia (UNEB), Campus X, \\ 45992-255, Teixeira de Freitas-BA, Brasil \\ ${ }^{2}$ Laboratório de Biologia dos Fungos, Departamento de Educação, Curso de Ciências Biológicas, Universidade do \\ Estado da Bahia (UNEB), Campus X, 45992-255, Teixeira de Freitas-BA, Brasil
}

*jfortuna@uneb.br

(Recebido em 21 de outubro de 2020; aceito em 26 de outubro de 2021)

\begin{abstract}
A fim de colaborar com o desenvolvimento sustentável, dentro da proposta de utilizar sistemas biológicos para tratamentos hídricos de baixo custo, propondo uma alternativa natural e limpa, a biorremediação, em especial a técnica de fitorremediação com macrófitas aquáticas, é uma estratégia que vem se destacando. $\mathrm{O}$ objetivo deste trabalho foi verificar a capacidade do aguapé Eichhornia azurea (Swartz) Kunth de depurar água contaminada por coliformes termotolerantes. $\mathrm{O}$ trabalho de pesquisa foi desenvolvido no Laboratório de Microbiologia da Universidade do Estado da Bahia (UNEB), Campus X, Teixeira de Freitas-BA. Inicialmente, foi realizada uma coleta da espécie no rio Itanhém. Após o período adaptativo, espécimes da planta foram distribuídos em quatro diferentes tanques, cada um contendo características distintas de nível de contaminação por coliformes. Foram realizadas coletas da água de cada tanque para análise microbiológica, semanalmente. Os dados obtidos foram estruturados em tabelas e gráficos. $\mathrm{O}$ método utilizado para testar a hipótese de diferença considerável entre os tanques de tratamento e o tempo de perda de contaminação da água foi Análise de Variância utilizando o teste $t$ de Student. Foi possível constatar a redução das populações de coliformes presentes nos tanques experimentais, onde o decaimento médio de coliformes foi de 3,34895 log NMP/100 mL. Além disso, foi realizada a análise do ganho de peso dos espécimes da planta, que chegaram a um ganho de até $64 \%$ do peso inicial. A espécie analisada apresentou potencial para uso em técnicas de fitorremediação.

Palavras-chave: aguapé, contaminação hídrica, fitodepuração.
\end{abstract}

In order to contribute with sustainable development, within the proposal to use biological systems for lowcost water treatments, proposing a natural and clean alternative, among the alternatives, bioremediation stands out, especially the phytoremediation technique with aquatic macrophytes. The objective of this work was to verify the capacity of water hyacinth Eichhornia azurea (Swartz) Kunth to clean water contaminated with thermotolerant coliforms. The research work was developed at the Microbiology Laboratory of the State University of Bahia (UNEB), Campus X, Teixeira de Freitas-BA. Initially, a collection of the species was carried out in the Itanhém River. After the adaptive period, specimens of the plant were distributed in four different tanks, each containing distinct characteristics of coliform contamination level. Weekly water collections were carried out from each tank for microbiological analysis. The data obtained were structured in tables and graphs, the method used to test the hypothesis of considerable difference between the treatment tanks and the time of loss of water contamination was the Variance Analysis using the Student's t-test. It was possible to observe the reduction of coliform populations present in the experimental tanks, where the mean decay of coliforms was $3.34895 \log \mathrm{NMP} / 100 \mathrm{~mL}$. In addition, the weight gain analysis of the plant specimens was performed, which reached an increment of up to $64 \%$ in relation to the initial weight. The analyzed species presented potential for use in phytoremediation techniques.

Keywords: water hyacinth, hydro contamination, phyto-depuration.

\section{INTRODUÇÃO}

Eichhornia azurea (Swartz) Kunth, espécie nativa da América tropical, é uma macrófita aquática flutuante, fundamental para o equilíbrio de ecossistemas naturais. Faz parte da família Pontederiaceae, pertencente ao gênero Eichhornia, sendo também conhecida popularmente em quase todas as regiões do Brasil por vários nomes diferentes: aguapé-de-baraço, aguapé-de- 
canudo, aguapé-de-cordão, baronesa, camalote, olhereira, dama-do-lago; além de outros nomes citados pela literatura, como: Piaropus azureus, Pontederia azurea, Eichhornia aquatica, Pontederia aquatica, sendo que esses nomes variam de acordo com a região de cultivo [1].

Segundo Oliveira Júnior (2011) [2], o aguapé possui características que o tornam um agente despoluidor de águas ou uma "praga", pois apresenta um rápido período de reprodução, além da sua capacidade de adaptação em diversos meios; como também, sua biomassa se expande com facilidade e causa bloqueamento de canais e rios. Entretanto, se o aguapé for manejado de forma correta, com manutenção adequada, pode se tornar um vetor de despoluição.

Diversos estudos recentes vêm destacando as potencialidades no uso de macrófitas aquáticas e possibilidades para sua utilização na depuração de ambientes eutrofizados, pois as mesmas vêm se destacando como alternativa em sistemas de tratamentos de efluentes, por exemplo o tratamento de esgoto doméstico [3].

A espécie possui potencial em fitorremediação de lagos com elevadas concentrações de nutrientes (eutrofizados), além da capacidade de absorver metais pesados, nutrientes de soluções e águas contaminadas [4]. De acordo com Pescod (1992) [5], o aguapé é utilizado em diversos países como alternativa empregada na fitodepuração, viabilizando a diminuição da matéria orgânica e metais pesados contidos em efluentes domésticos. Os níveis de matéria orgânica, contido em lagos e córregos, são um fator determinante para a utilização da água, pois geralmente os sistemas de esgoto doméstico não tratados deságuam nestes meios, deixando-os contaminados com diversos microrganismos patogênicos que tornam a água inviável para o consumo.

Escherichia coli é uma bactéria pertencente aos grupos de coliformes totais e de termotolerantes. Faz parte do trato intestinal do homem e de outros animais de sangue quente, sendo encontrada nas fezes de todos os indivíduos normais; o que fez $E$. coli ser escolhida desde 1892, para atuar como indicadora dos testes de verificação de contaminação fecal da água e alertar a presença de patógenos, sendo bastante utilizada na saúde pública $[6,7]$.

O tratamento de efluentes domésticos através do sistema de tanques, proposto por Salati (2000) [8], pode ser uma estratégia bastante aplicável, visto que, as técnicas utilizadas nos tratamentos convencionais muitas vezes são de custo elevado e, frequentemente, não apresentam eficiência satisfatória [9]. Os Sistemas Wetlands, denominados de Terras Úmidas Construídas ou Alagados Construídos, são sistemas desenhados que se constituem de tanques, lagoas ou canais artificiais rasos contendo plantas aquáticas que metabolizam junto com a microbiota o tratamento de esgotos sanitários de até 20 mil habitantes [10]. O tratamento basicamente consiste no cultivo de macrófitas aquáticas flutuantes que propiciam a redução de nutrientes e sólidos suspensos do efluente, por meio de sistema confinado de tanques [11, 12].

Considerando esse contexto, a presente pesquisa tem como objetivo verificar a capacidade do aguapé Eichhornia azurea (Swartz) Kunth de depurar água contaminada por coliformes termotolerantes.

\section{MATERIAL E MÉTODOS}

Este estudo foi realizado com águas coletadas do rio Itanhém (20 litros) (17³0'43.952"S; 3943'13.796”O) e do córrego do Penteado (10 litros) (17³2'51.673”'S; 3944'26.693”O). Os locais de coleta de Eichhornia azurea foram determinados a partir da facilidade de acesso da região. As amostras de água e da planta, para análise e utilização no experimento, foram transportadas até o Campus $\mathrm{X}$ da Universidade do Estado da Bahia (UNEB), localizado no município de Teixeira de Freitas-BA.

Neste estudo foram utilizadas a água de dois recursos hídricos da região, o rio Itanhém e o córrego do Penteado, para justificar o uso da técnica de fitorremediação em águas poluídas. O rio Itanhém, também chamado de rio Alcobaça, é um rio que passa pelas cidades baianas de Itanhém; Medeiros Neto; Teixeira de Freitas e Alcobaça, desaguando na Praia da Barra de Alcobaça. O rio nasce na aldeia dos Machacalis no município de Fronteira dos Vales, estado de Minas Gerais e transcorre de oeste para leste até a foz em Alcobaça, onde deságua no Oceano Atlântico. Seu principal afluente é o rio Itanhetinga (80 km de extensão), que fica na margem esquerda. Seus 
outros principais afluentes são: rio das Umburanas (55 km de extensão), rio Água Fria (56 km de extensão) e córrego da Bandeira (48 km de extensão).

O córrego do Penteado, fica localizado no município de Teixeira de Freitas-BA. Devido à construção de casas próximo da localização de sua nascente e a canalização, fica muito impreciso determinar o exato ponto, sendo necessário admitir o possível olho d'água na rua Dois Irmãos, no bairro São Lourenço. Este córrego recebe um intenso despejo de esgoto doméstico in natura, aporte de lixo doméstico e resíduos de construção civil.

As amostras de água foram coletadas em galões previamente higienizados com água deionizada esterilizada e solução de hipoclorito de sódio a $1,5 \%$.

Foi realizada uma pesquisa qualitativa baseada no sistema de Wetland (sistema de alagados artificiais) proposto por Salati (2000) [8], e posterior escolha da macrófita aquática flutuante que melhor se encaixou com a proposta da pesquisa.

Para seleção da espécie de macrófita, foi estabelecido um padrão de classificação: facilidade de adaptação, menor período de reprodução e maior capacidade de produção de biomassa na região Teixeira de Freitas-BA. Eichhornia azurea (Swartz) Kunth foi a espécie que melhor atendeu aos critérios de classificação; além disso, é uma das espécies mais utilizadas em sistema de tanques com canais relativamente rasos. De acordo com o Instituto de Ecologia Aplicada (IEA), os tanques de tratamento podem conter apenas uma espécie de planta ou uma combinação de espécies [13].

A identificação final das amostras coletadas de Eichhornia azurea (Swartz) Kunth foi baseada em informações e chaves contidas em artigos científicos [14-16] e no site do Herbário Virtual do Jardim Botânico do Rio de Janeiro [17].

A pesquisa foi desenvolvida no Laboratório de Microbiologia da Universidade do Estado da Bahia (UNEB), Campus X, onde foram realizadas a montagem do experimento e as análises das condições microbiológicas da água em quatro tanques de diferentes tratamentos. Todo o processo da pesquisa foi realizado após 30 dias da instalação do sistema de tanques. Esse período foi destinado à adaptação biológica da espécie Eichhornia azurea, inserida no novo ambiente [18].

Após o período de adaptação da planta, os espécimes da macrófita Eichhornia azurea, estas foram higienizadas em água corrente; posteriormente, colocadas em solução de hipoclorito de sódio a $1,5 \%$ por 10 minutos e depois imediatamente enxaguadas em água deionizada esterilizada. Após a higienização das amostras das plantas, estas foram pesadas individualmente e anotadas suas massas iniciais (Figura 1).

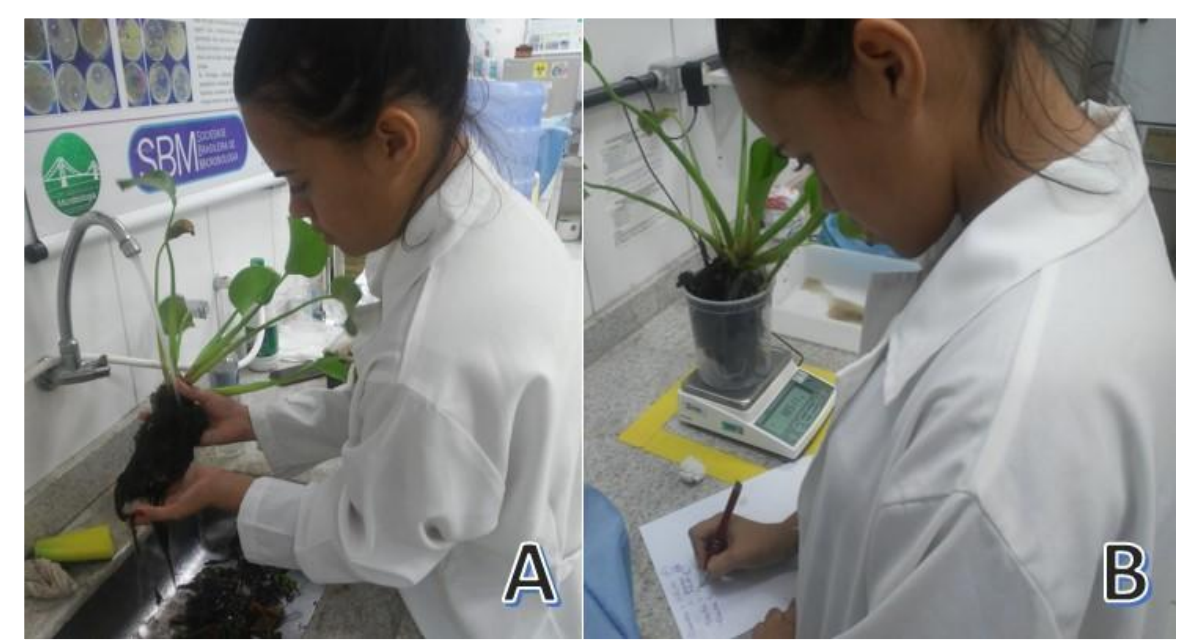

Figura 1. (A) Lavagem da amostra de Eichhornia azurea em água corrente. (B) Pesagem inicial da amostra da planta antes de colocar no tanque. 


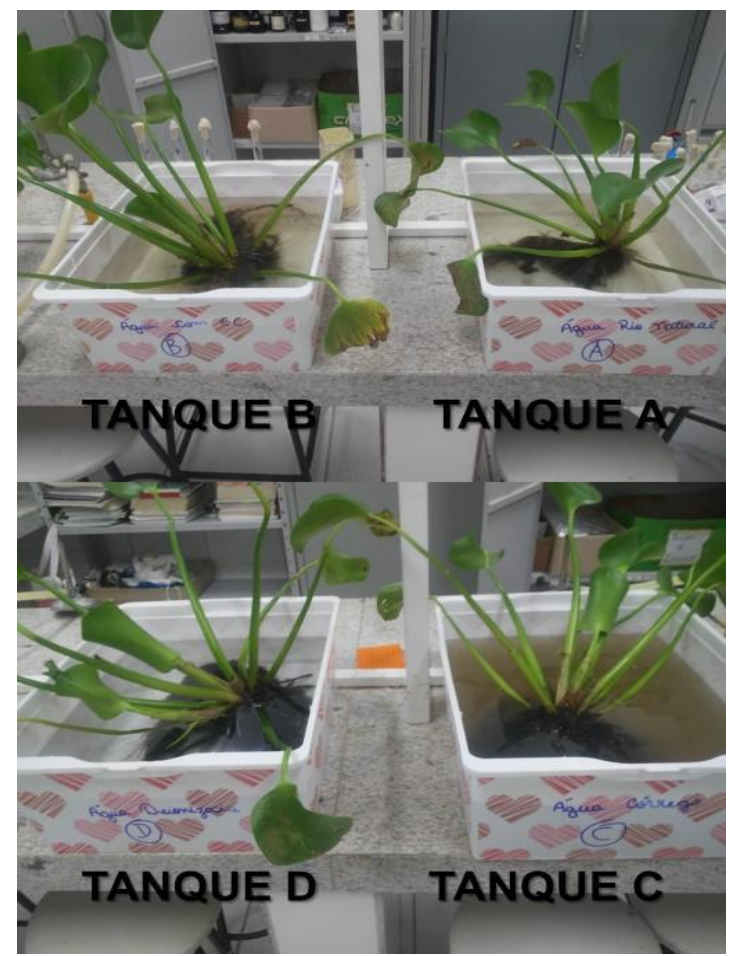

Figura 2. Espécimes de Eichhornia azurea colocados nos quatro diferentes tanques experimentais.

Depois cada espécime da planta foi colocado nos quatro diferentes tanques experimentais. Cada tanque apresentava as seguintes dimensões: 41×28x27 cm (comprimento, largura e profundidade) (Figura 2). No TANQUE A foram colocados dez litros de água coletada do rio Itanhém, em um ponto que a princípio se encontrava sem contaminação por coliformes termotolerantes. O TANQUE B foi preenchido por dez litros de água coletada no rio Itanhém que foi contaminada artificialmente com $10 \mathrm{~mL}$ de Solução Salina $(0,85 \%)$ previamente contaminada com $6,0 \times 10^{8}$ bactérias $/ \mathrm{mL}$ de Escherichia coli (coliformes termotolerantes) (controle positivo), de acordo com a escala 2,0 de McFarland. O TANQUE C possuía dez litros de água coletada do córrego do Penteado que naturalmente encontrava-se contaminado por coliformes termotolerantes. A confirmação da contaminação foi feita por análise bacteriológica. O TANQUE D continha dez litros de água deionizada esterilizada (controle negativo). A confirmação da pureza da água foi realizada através de análise bacteriológica (Figura 3).
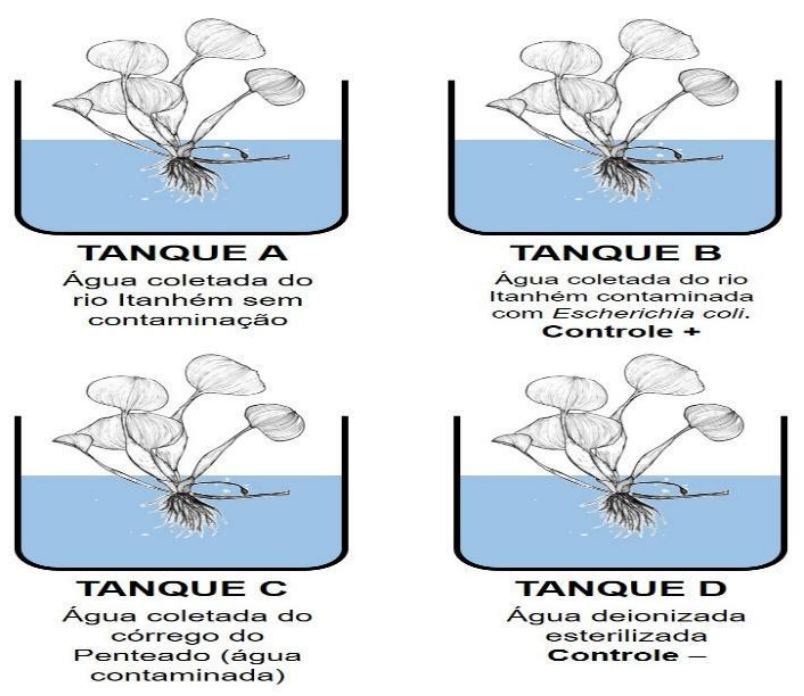

Figura 3. Esquema para identificação dos tanques de tratamento. 
Para obter a confirmação da contaminação da água dos tanques $\mathbf{B}$ e $\mathbf{C}$ ou da pureza da água dos tanques A e $\mathbf{D}$ foram realizadas análises microbiológicas das águas dos diferentes tanques utilizando o método do Número Mais Provável (NMP) ou técnica dos tubos múltiplos, de acordo com Silva et al. (2007) [7].

Os tanques foram colocados sobre um jardim, no lado de fora do Laboratório de Microbiologia, em um espaço natural onde recebiam luz natural do Sol em vários momentos do dia, sendo que não receberam influência da água da chuva, pois estavam sob uma marquise de alvenaria (Figura 4). Durante todo o experimento, a água não foi trocada, como também não foi adicionado mais água. A cada dois dias, a água de todos os tanques era homogeneizada utilizando um bastão de vidro previamente higienizado com álcool $70 \%$.

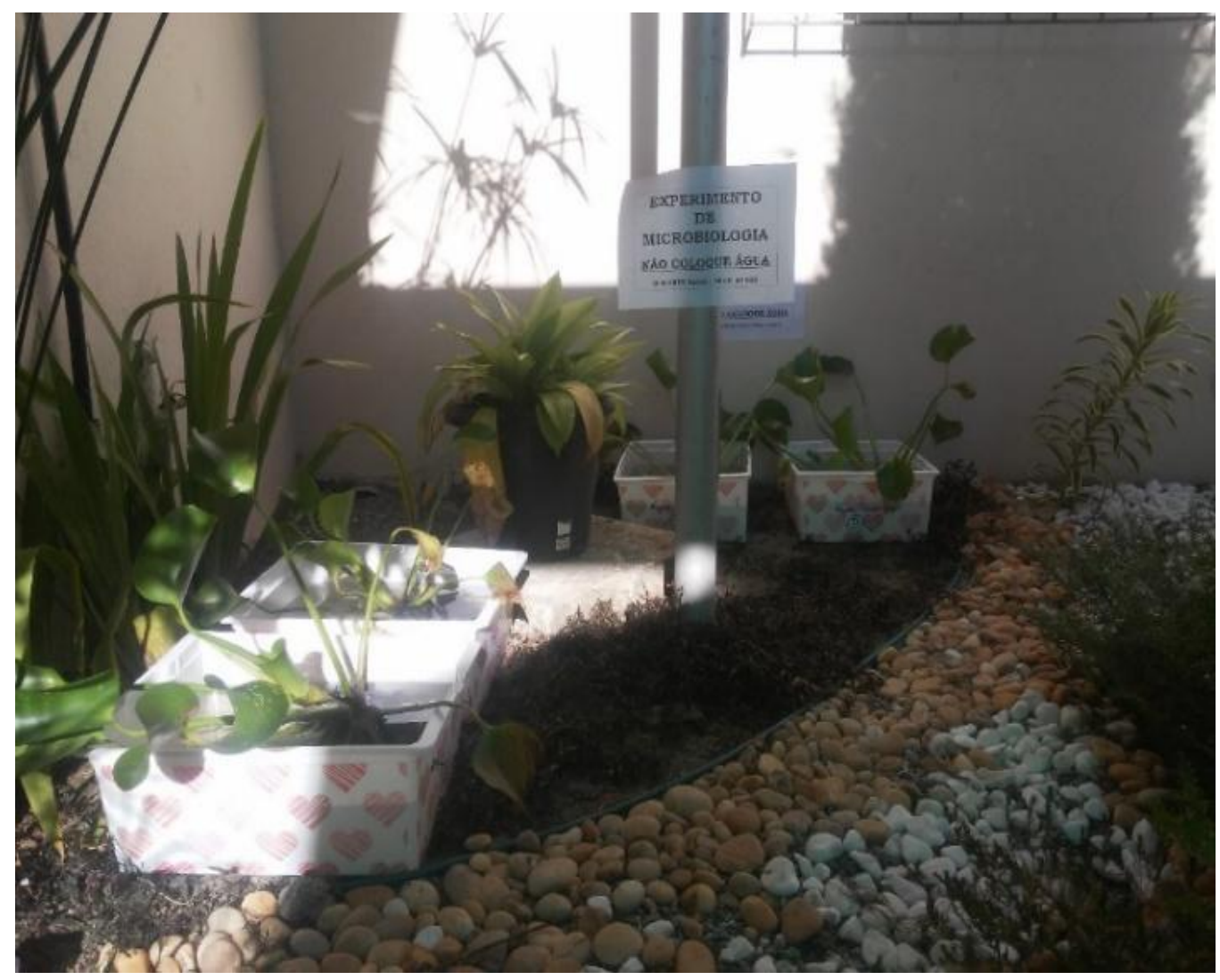

Figura 4. Tanques do experimento colocados sobre um jardim, no lado de fora do Laboratório de Microbiologia da UNEB.

Para a contaminação dos 10 litros de água do rio Itanhém, que foram colocados no TANQUE B, utilizou-se cepas de Escherichia coli INCQS 00031 (ATCC 10536) que foram doadas da Coleção de Microrganismos de Referência em Vigilância Sanitária (CMRVS) do Instituto Nacional de Controle de Qualidade em Saúde (INCQS), da Fundação Oswaldo Cruz (FIOCRUZ), localizado no Rio de Janeiro-RJ. Inicialmente, para ativação das cepas bacterianas, as mesmas foram crescidas em tubos de ensaio contendo Ágar Nutriente (AN) e mantidas em estufa a $37{ }^{\circ} \mathrm{C}$ por 18 horas.

Após a incubação, as colônias de E. coli foram transferidas para um novo tubo contendo 10 $\mathrm{mL}$ de Solução Salina $(0,85 \%)$, até atingir a turvação de 2,0 na escala de McFarland, equivalente a $6,0 \times 10^{8} \mathrm{UFC} / \mathrm{mL}$ (Figura 5). Logo em seguida esta solução do tubo foi vazada no TANQUE B contaminando a água, na proporção de 1:1.000 (v/v). 


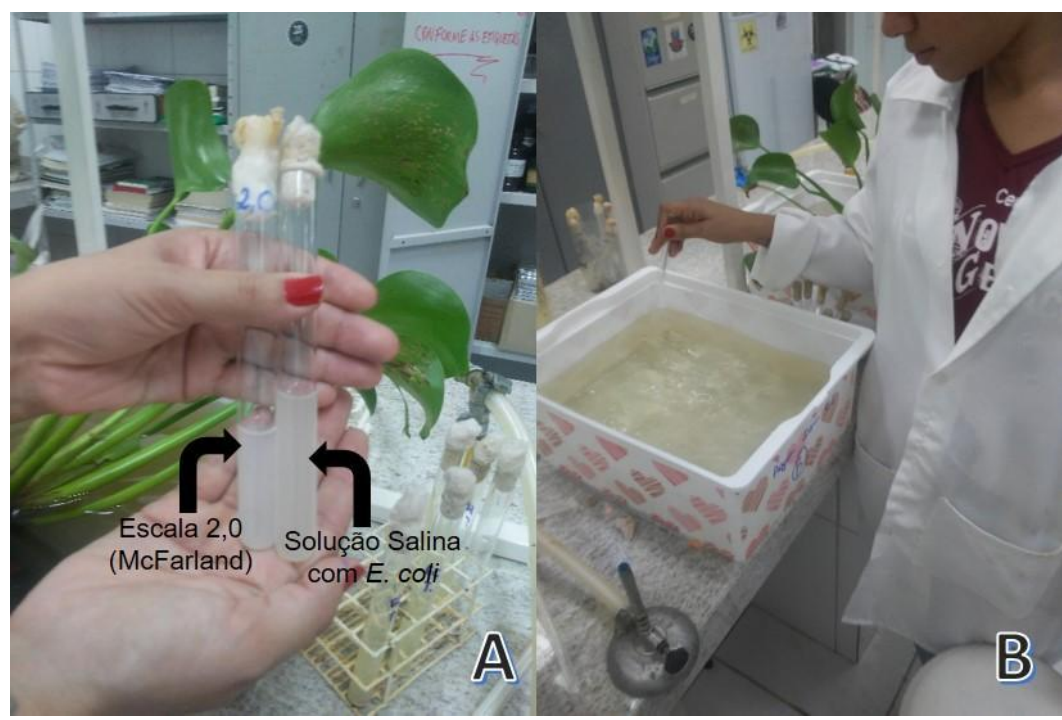

Figura 5. (A) Preparação da solução salina contaminada com Escherichia coli de acordo com a escala de McFarland. (B) Homogeneização da água após inoculação de E. coli na água do tanque B.

No primeiro dia do experimento (03/03/2020), ao término da colocação dos espécimes da planta em seus respectivos tanques, foram coletados $10 \mathrm{~mL}$, de cada tanque, para a contagem de coliformes totais e termotolerantes, determinando assim o tempo inicial das análises (T0). $\mathrm{O}$ intervalo das coletas da água dos diferentes tanques foi de uma semana (sete dias). Foram realizadas três coletas, sendo identificadas como $1^{\mathrm{a}}$ coleta (T0) no dia $03 / 03 / 2020 ; 2^{\mathrm{a}}$ coleta (T1) no dia (10/03/2020) e $3^{a}$ coleta (T2) no dia (17/03/2020).

Para cada amostra de $10 \mathrm{~mL}$ de água coletada nos respectivos tanques $(\mathbf{A}, \mathbf{B}, \mathbf{C}$ e D) utilizouse a técnica do número mais provável para a enumeração de coliformes totais e termotolerantes [7]. Foram realizadas as diluições das amostras a partir de $1,0 \mathrm{~mL}$ de água em $9,0 \mathrm{~mL}$ de Solução Salina Peptonada (SSP) a $0,1 \%$ formando a diluição $10^{-1}$. Após homogeneizado, transferiu-se, com o auxílio da pipeta, $1,0 \mathrm{~mL}$ da diluição $10^{-1}$ para tubo de ensaio contendo $9,0 \mathrm{~mL}$ de SSP de modo a obter diluição de $10^{-2} \mathrm{e}$ assim sucessivamente para formar as diluições $10^{-3}, 10^{-4} \mathrm{e} 10^{-5}$.

Para a realização do teste presuntivo utilizou-se $10,0 \mathrm{~mL}$ do Caldo Lauril Sulfato Triptose (LST) em tubos de ensaio contendo tubos de fermentação. Transferiu-se, com o auxílio de uma micropipeta, $1,0 \mathrm{~mL}$ de cada diluição $\left(10^{-1} ; 10^{-2} ; 10^{-3} ; 10^{-4}\right.$ e $\left.10^{-5}\right)$ de SSP para três séries de tubos contendo LST. Após a inoculação os tubos de LST foram incubados em estufa bacteriológica a $35^{\circ} \mathrm{C} / 24-48 \mathrm{~h}$.

Os tubos que apresentaram turvação do meio de cultura com presença de gás nos tubos de Durhan foram considerados positivos, seguindo-os para os testes confirmativos para coliformes totais e termotolerantes.

Para o teste confirmativo de coliformes totais utilizaram-se tubos de ensaio com 10,0 mL do Caldo Verde Brilhante Bile Lactose (VBBL), também com tubos de Durhan invertido. Após a inoculação no meio, utilizando a alça bacteriológica, a partir dos tubos de LST positivos, os tubos de VBBL foram incubados em estufa a $35^{\circ} \mathrm{C} / 24-48 \mathrm{~h}$. Os tubos que produziram gás no interior do tubo de Durham e turvação do meio foram considerados positivos e tiveram seus resultados anotados.

Já para o teste confirmativo de coliformes termotolerantes utilizaram-se tubos de ensaio com 10,0 mL do Caldo para Escherichia coli (EC), também com tubos de Durhan invertido. Após a inoculação no meio, utilizando a alça bacteriológica, a partir dos tubos de LST positivos, os tubos de EC foram incubados em estufa banho-maria a $45^{\circ} \mathrm{C} / 24-48 \mathrm{~h}$. Os tubos que produziram gás no interior do tubo de Durham e turvação do meio foram considerados positivos e tiveram seus resultados anotados.

Ao fim de cada teste foi efetuada a leitura de seus respectivos resultados, de acordo com o número de tubos positivos em cada uma das diluições e das fases utilizadas, foi determinado o 
Número Mais Provável (NMP) de células bacterianas pertencentes ao grupo dos coliformes totais e termotolerantes, sendo estes comparados com os valores da tabela de Hoskins.

Para o cálculo de rendimento da perda de contaminação de coliformes termotolerantes na água dos tanques contaminados (Tanques B e C), foram registrados a enumeração de bactérias do grupo coliformes termotolerantes, através do $\mathrm{NMP} / \mathrm{mL}$, inicial e depois a enumeração final, ao término do experimento, utilizando a equação abaixo (Equação 1).

$$
\mathrm{RC} \%=[(C i-C f) / C i] \times 100
$$

(Equação 1)

Onde RC\% = Rendimento de perda de contaminação da água (\%); $C i=$ Contaminação inicial da água por coliformes termotolerantes $(\mathrm{NMP} / \mathrm{mL})$; e $C f=$ Contaminação final da água por coliformes termotolerantes $(\mathrm{NMP} / \mathrm{mL})$.

Para o cálculo de rendimento do crescimento da planta, nos diferentes tanques, foram pesados os espécimes da planta separadamente antes de serem colocados nos respectivos tanques e depois de retirados dos tanques, ao final do experimento (Equação 2).

$$
\mathrm{RP} \%=[(P f-P i) / P i] \times 100
$$

(Equação 2)

Onde RP $\%=$ Rendimento de crescimento da planta (\%); $P i=$ Peso inicial da planta em gramas $(\mathrm{g}) ;$ e $P f=$ Peso final da planta em gramas $(\mathrm{g})$.

Os dados coletados foram estruturados em tabelas, facilitando a organização de gráficos. A Análise de Variância (ANOVA: dois critérios), utilizando o teste $t$ de Student [19], foi o método utilizado para testar a hipótese de diferença considerável entre os tanques de tratamento e o tempo de perda de contaminação da água.

\section{RESULTADOS E DISCUSSÃO}

Foi observado que a macrófita Eichhornia azurea possui capacidade de absorção de contaminantes biológicos, demonstrando a diminuição da enumeração de coliformes totais e termotolerantes na água do tanque $\mathbf{B}$ (água do rio Itanhém contaminada artificialmente) e do tanque $\mathbf{C}$ (água do córrego do Penteado contaminada naturalmente) (Tabela 1; Figura 6).

Tabela 1. Resultados da enumeração de coliformes totais e termotolerantes das águas dos respectivos

\begin{tabular}{|c|c|c|c|c|c|}
\hline \multirow{2}{*}{ COLETAS } & \multirow{2}{*}{ COLIFORMES } & \multicolumn{4}{|c|}{ Coliformes $(\mathrm{NMP} / 100 \mathrm{~mL})(\log )^{* 2}$} \\
\hline & & TANQUE A*4 & TANQUE B & TANQUE C & TANQUE D \\
\hline \multirow{2}{*}{$\begin{array}{c}\mathbf{1}^{\text {a }} \text { Coleta } \\
(\mathrm{T} 0)^{* 1}\end{array}$} & Totais & $\begin{array}{l}4,3 \times 10^{3} \\
(3,6335)\end{array}$ & $\begin{array}{c}1,1 \times 10^{8} \\
(8,0414)\end{array}$ & $\begin{array}{c}2,4 \times 10^{7} \\
(7,3802)\end{array}$ & $\begin{array}{l}\text { Ausente } \\
(0,0000)\end{array}$ \\
\hline & Termotolerantes & $\begin{array}{l}3,6 \times 10^{2} \\
(2,5563)\end{array}$ & $\begin{array}{c}1,1 \times 10^{8} \\
(8,0414)\end{array}$ & $\begin{array}{l}2,4 \times 10^{7} \\
(7,3802)\end{array}$ & $\begin{array}{l}\text { Ausente } \\
(0,0000)\end{array}$ \\
\hline \multirow{2}{*}{$\begin{array}{l}2^{\text {a }} \text { Coleta } \\
\text { (T1) }\end{array}$} & Totais & $\begin{array}{l}\text { Ausente } \\
(0,0000)\end{array}$ & $\begin{array}{l}7,5 \times 10^{5} \\
(5,8751)\end{array}$ & $\begin{array}{l}9,3 \times 10^{4} \\
(4,9685)\end{array}$ & $\begin{array}{l}3,6 \times 10^{2} \\
(2,5563)\end{array}$ \\
\hline & Termotolerantes & $\begin{array}{l}\text { Ausente } \\
(0,0000)\end{array}$ & $\begin{array}{l}7,5 \times 10^{5} \\
(5,8751)\end{array}$ & $\begin{array}{l}9,3 \times 10^{4} \\
(4,9685)\end{array}$ & $\begin{array}{l}\text { Ausente } \\
(0,0000)\end{array}$ \\
\hline \multirow{2}{*}{$\begin{array}{c}3^{\text {a }} \text { Coleta } \\
\text { (T2) }\end{array}$} & Totais & $\begin{array}{l}\text { Ausente } \\
(0,0000)\end{array}$ & $\begin{array}{l}3,6 \times 10^{4} \\
(4,5563)\end{array}$ & $\begin{array}{c}1,5 \times 10^{3} \\
(3,1761)\end{array}$ & $\begin{array}{l}3,6 \times 10^{2} \\
(2,5563)\end{array}$ \\
\hline & Termotolerantes & $\begin{array}{l}\text { Ausente } \\
(0,0000)\end{array}$ & $\begin{array}{l}3,6 \times 10^{4} \\
(4,5563)\end{array}$ & $\begin{array}{c}1,5 \times 10^{3} \\
(3,1761)\end{array}$ & $\begin{array}{l}3,6 \times 10^{2} \\
(2,5563)\end{array}$ \\
\hline \multirow{2}{*}{$\begin{array}{l}\text { Média*3 } \\
\text { (Desvio } \\
\text { Padrão) }\end{array}$} & Totais & $\begin{array}{l}1,2112 \\
( \pm 2,10)\end{array}$ & $\begin{array}{l}6,1576 \\
( \pm 1,76)\end{array}$ & $\begin{array}{l}5,1749 \\
( \pm 2,11)\end{array}$ & $\begin{array}{l}1,7042 \\
( \pm 1,48)\end{array}$ \\
\hline & Termotolerantes & $\begin{array}{l}0,8521 \\
( \pm 1,48)\end{array}$ & $\begin{array}{l}6,1576 \\
( \pm 1,76)\end{array}$ & $\begin{array}{l}5,1749 \\
( \pm 2,11)\end{array}$ & $\begin{array}{l}0,8521 \\
( \pm 1,48)\end{array}$ \\
\hline $\begin{array}{l}*^{1} \text { T0 (tempo ini } \\
*^{2} \text { Entre parênte } \\
{ }^{* 3} \text { Valor da méd } \\
{ }^{* 4} \text { Tanque A (ág }\end{array}$ & $\begin{array}{l}\text { T1 (tempo um); T2 } \\
\text { valor do NMP/100 m } \\
\text { NMP/100 mL em lo } \\
\text { rio Itanhém sem con }\end{array}$ & $\begin{array}{l}\text { dois). } \\
\text { logaritmo. } \\
\text { lo; entre parêntes } \\
\text { ação); Tanque B }\end{array}$ & $\begin{array}{l}\text { Desvio Padrão. } \\
\text { a do rio Itanhén }\end{array}$ & taminada ar & nente); Tanque \\
\hline
\end{tabular}
tanques durante as três coletas. 
O Tanque A, contendo água do rio Itanhém, apresentou a menor população inicial de coliformes, sendo estes de 3,6335 log NMP/100 mL para coliformes totais e 2,5563 log NMP/100 $\mathrm{mL}$ para termotolerantes; e a partir da segunda semana após a inserção do sistema, não foi observada a presença de coliformes totais e termotolerantes, o que mostra um tratamento eficiente desta macrófita para o reuso dessa água (Tabela 1). Almeida e Almeida (2006) [20] relataram remoção acima de $99,5 \%$ de coliformes totais e fecais de efluente de esgoto em sua pesquisa. Pinto et al. (2009) [21] fizeram pesquisa com macrófitas flutuantes para tratamento de efluentes de carcinicultura e verificaram a redução da contaminação por $E$. coli de $88,23 \%$.

O Tanque B, composto por água do rio Itanhém contaminada artificialmente com E. coli, apontou uma considerável diminuição no número de microrganismos, tendo o seu número de coliformes iniciais de 8,0414 $\log \mathrm{NMP} / 100 \mathrm{~mL}$; sendo reduzidos a 4,5563 $\log \mathrm{NMP} / 100 \mathrm{~mL}$ ao final da terceira semana $(43,34 \%)$ (Tabelas 1 e 2 ).

O Tanque C, integrado pela água do córrego do Penteado, mostrou um excelente resultado, sendo sua população de coliformes totais e termotolerantes inicial de 7,3802 log NMP/100 mL; decrescendo a 3,1761 log NMP/100 mL (56,96\%) (Tabelas 1 e 2). Resultados semelhantes foram encontrados em um estudo realizado por Borba et al. (2018) [22].

O Tanque D, comportando água deionizada esterilizada, mostrou um crescimento da população de coliformes totais e termotolerantes a partir da segunda semana, após a sua inserção no tanque, passando de ausência de coliformes $(0,00 \log \mathrm{NMP} / 100 \mathrm{~mL})$ a 2,5563 log NMP/100 $\mathrm{mL}$ (Tabela 1). Porém, esse valor está de acordo com a resolução CONAMA $\mathrm{n}^{\circ} 357$ que determina que o valor do efluente tratado não pode exceder o valor máximo de $1.000 \mathrm{NMP} / 100 \mathrm{~mL}$ ou 3,0 $\log \mathrm{NMP} / 100 \mathrm{~mL}$ de amostra analisada [23].

Interessante verificar a diminuição gradual do nível de contaminação por coliformes tanto no Tanque B (controle +), quanto no Tanque C (água do córrego contaminada por coliformes), confirmando que a planta apresenta capacidade de baixar os níveis de contaminação encontrada na água (Figura 6).

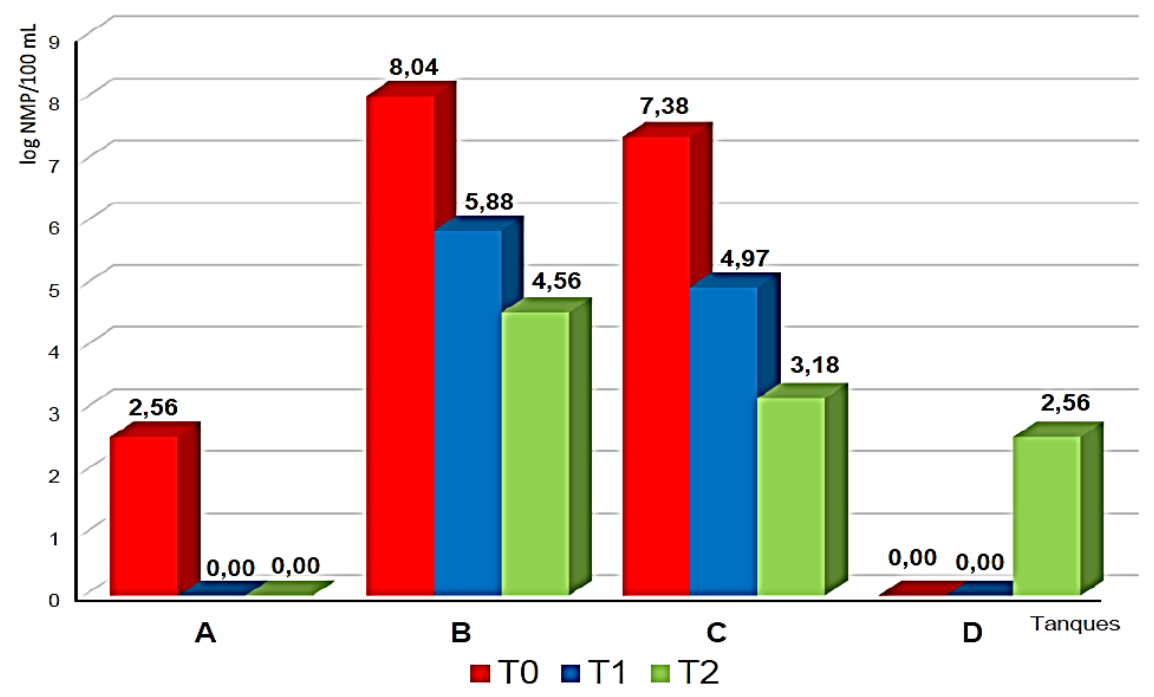

Figura 6. Resultados da enumeração de coliformes termotolerantes (log NMP/100 mL) das águas dos respectivos tanques durante as três coletas (T0; T1; T2).

Utilizando-se o teste $t$ de Student (ANOVA: dois critérios) verificou-se que houve diferença significativa $(p=0,0112)$ entre os tanques contaminados $(\mathbf{B}$ e $\mathbf{C})$ e os tanques não contaminados (A e D), ao nível de significância $\alpha=0,05$, porém não houve diferença significativa $(p=0,1289)$ entre os tempos (T0; T1: T2) de coleta e enumeração do nível de contaminação da água dos tanques. 
Diversos autores já obtiveram resultados semelhantes na redução de nível de contaminação em águas por coliformes totais e termotolerantes em tratamentos utilizando macrófitas [24-28] e os resultados obtidos no presente trabalho corroboram esses estudos.

Diniz et al. (2005) [29] verificaram redução de coliformes termotolerantes entre $35 \%$ e $98 \%$ e de estreptococos fecais entre $35 \%$ e $88 \%$, após a passagem da água pelo banco de macrófitas. As reduções de coliformes totais e fecais foram satisfatórias e os resultados desta pesquisa estão de acordo com os encontrados na literatura [30].

Em relação a enumeração de coliformes termotolerantes presentes nos tanques durante o período do experimento, nos Tanques A e D (controle negativo) houve uma redução média de 1,2112 log NMP/100 mL para coliformes termotolerantes e de 0,8521 log NMP/100 mL para coliformes totais e comparando-os observou-se que em cada tanque houve diminuição na enumeração de coliformes. No Tanque B (controle positivo) redução média foi de 6,1576 log $\mathrm{NMP} / 100 \mathrm{~mL}$ para coliformes totais e termotolerantes, apresentando um decaimento sem significância estatística quando comparado ao Tanque $\mathbf{C}$, onde a redução média foi de 5,1749 $\log \mathrm{NMP} / 100 \mathrm{~mL}$ para coliformes totais e termotolerantes (Figura 7).

Observou-se significativo declínio nas populações de coliformes totais e termotolerantes nos Tanques B e C, onde a redução média de coliformes nestes tanques foi de 3,34895 log NMP/100 mL (Tabela 2). Segundo Esteves e Camargo (1986) [31], as macrófitas aquáticas estocam e retêm em sua biomassa nutrientes contidos em ecossistemas aquáticos, fazendo com que os níveis de eutrofização decaiam.

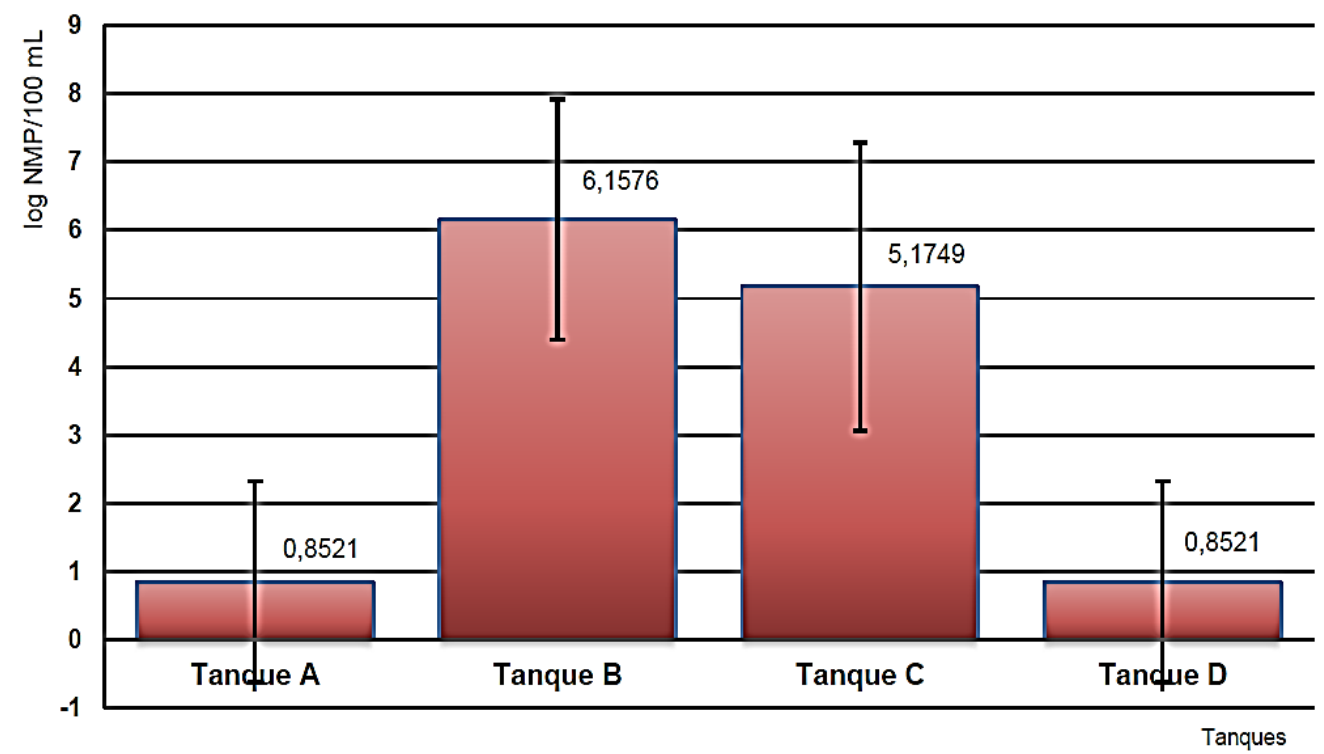

Figura 7. Resultado das médias e desvio padrão da enumeração de coliformes termotolerantes (log $N M P / 100 \mathrm{~mL}$ ) da água dos diferentes tanques.

Tabela 2. Rendimento da perda de coliformes na água dos tanques contaminados com Escherichia coli.

\begin{tabular}{ccccc}
\hline ANQUES & $\begin{array}{c}\text { Contaminação } \\
\text { Inicial (Ci) em } \\
\log \text { NMP/100 mL }\end{array}$ & $\begin{array}{c}\text { Contaminação } \\
\text { Final (Cf) em log } \\
\text { NMP/100 mL }\end{array}$ & $\begin{array}{c}\text { Perda de } \\
\text { Contaminação (Ci-Cf) } \\
\text { em log NMP/100 mL }\end{array}$ & $\begin{array}{c}\text { Rendimento da Perda de } \\
\text { Contaminação (\%) }\end{array}$ \\
\hline B & 8,0414 & 4,5563 & 3,4851 & $43,34 \%$ \\
C & 7,3802 & 3,1761 & 4,2041 & $56,96 \%$ \\
\hline Média & $\mathbf{7 , 7 1 0 8}$ & $\mathbf{3 , 8 6 6 2}$ & $\mathbf{3 , 8 4 4 6}$ & $\mathbf{4 9 . 8 6 \%}$ \\
\hline
\end{tabular}


O porcentual médio do rendimento da diminuição de contaminação por coliformes nos Tanques B e C foi de 49,86\% (Tabela 2), indicando que E. azurea apresenta potencial para uso em fitorremediação em ambientes eutrofizados.

Em outros trabalhos utilizando plantas macrófitas para diminuição do nível de contaminação da água, Souza e Bernardes (1996) [32] conseguiram uma média próxima a 54\% de redução em esgoto doméstico. Já Souza et al. (2000) [33] alcançou uma perda de contaminação de 76\% em wetlands com descargas hidráulicas, e Sezerino e Philippi (2000) [34] indicaram uma eficiência de remoção de $87 \%$ da matéria orgânica e de $99,96 \%$ de coliformes termotolerantes.

Em relação a biomassa das macrófitas, os espécimes foram inseridos in natura nos respectivos tanques com uma biomassa inicial média de $274,86 \mathrm{~g}$. No final da terceira semana, ao serem novamente pesadas, as macrófitas obtiveram um rendimento de ganho de massa médio $30,71 \%$ (Tabela 3; Figura 8). Segundo diversos autores, o crescimento da planta está relacionado com a remoção dos poluentes presentes na água, isto é, a partir da diminuição dos microrganismos contaminantes presentes na água, os espécimes da planta passam a se desenvolver melhor e ganhar peso [35-44].

Tabela 3. Registro dos pesos iniciais, pesos finais, ganho de massa e rendimento do ganho de massa dos espécimes da planta que foram colocados nos respectivos tanques do experimento.

\begin{tabular}{ccccc}
\hline TANQUES & $\begin{array}{c}\text { Peso Inicial da } \\
\text { Planta (Pi) em } \\
\text { gramas (g) }\end{array}$ & $\begin{array}{c}\text { Peso Final da } \\
\text { Planta (Pf) em } \\
\text { gramas (g) }\end{array}$ & $\begin{array}{c}\text { Ganho de Massa } \\
(\text { Pf-Pi) em gramas } \\
(\mathbf{g})\end{array}$ & $\begin{array}{c}\text { Rendimento do Ganho de } \\
\text { Massa (\%) }\end{array}$ \\
\hline A & 152,90 & 209,42 & 56,52 & $36,97 \%$ \\
B & 295,42 & 368,55 & 73,13 & $24,75 \%$ \\
C & 266,11 & 438,45 & 172,34 & $64,76 \%$ \\
D & 385,11 & 420,66 & 35,55 & $9,23 \%$ \\
\hline Média & $\mathbf{2 7 4 , 8 6}$ & $\mathbf{3 5 9 , 2 7}$ & $\mathbf{8 4 , 3 9}$ & $\mathbf{3 0 , 7 1 \%}$ \\
\hline
\end{tabular}

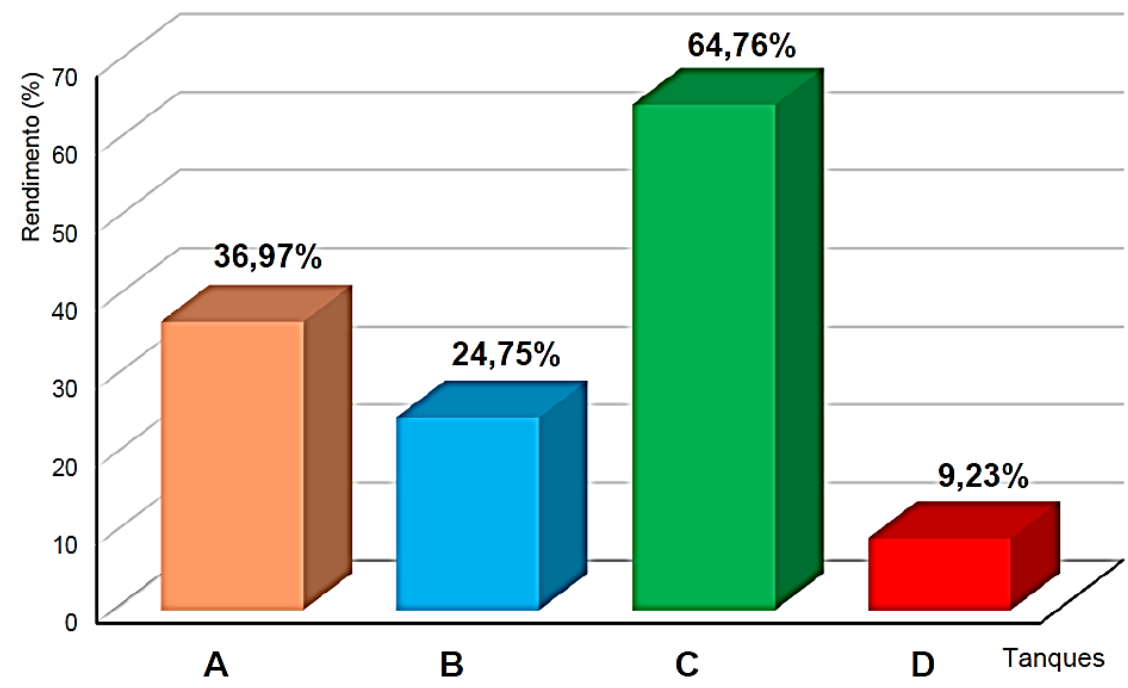

Figura 8. Resultados do rendimento de ganho de massa dos espécimes da planta que foram colocados nos respectivos tanques do experimento.

A biomassa adquirida pela planta durante o período de três semanas variou de acordo com o tanque em que ela estava inserida, apresentando a melhor produção de biomassa no Tanque $\mathbf{C}$, chegando a um aumento de $64,76 \%$ de seu peso inicial, indicando a capacidade desta planta em realizar fitorremediação em ambientes poluídos com matéria orgânica. De acordo com Perazza et al. (1985) [45] o período para a duplicação do tamanho da planta tem uma média de duas semanas. 
Bianchini Junior et al. (2010) [46] encontrou valores do tempo de duplicação variando entre 1,4 e 115 dias.

Observou-se que nas quatro wetlands estudadas houve o crescimento da macrófita de maneira significativa, no Tanque A o crescimento foi de $36,97 \%$, demonstrando que houve uma eficiente retenção de nutrientes pela planta. Em relação ao ganho de massa da planta no Tanque B de 24,75\%, Hamaamin et al. (2014) [47]; Mclain e Williams (2008) [48] apontam outras variáveis relacionadas com a absorção de nutrientes e crescimento da planta, não apenas parâmetros microbiológicos, mas também físico-químicos. Henry-Silva et al. (2002) [49], estudando o efeito da concentração de nutrientes, constataram um crescimento significativamente menor em baixas concentrações de nitrogênio e fósforo. No Tanque $\mathbf{D}$ o rendimento do ganho de massa foi de 9,23\%. De acordo com Silvestri (2010) [50] e Sipaúba-Tavares (2000) [51], quando a matéria orgânica presente na água acaba, o ganho de peso diminui e até inverte, alguns exemplares morrem e servem de alimento a outros, gerando o equilíbrio do sistema. Sendo assim, esses resultados permitiram concluir que os quatro tratamentos tiveram um ganho de massa de acordo com a característica apresentada por cada wetland.

\section{CONCLUSÃO}

O aguapé (Eichhornia azurea) possui um eficiente potencial biorremediador em águas eutrofizadas contendo coliformes totais e termotolerantes, mostrando uma eficácia na depuração de água contaminada.

O rendimento de ganho de biomassa das macrófitas está relacionado com diversos parâmetros além dos microbiológicos, podendo afetar o desenvolvimento da planta. O desempenho do sistema na remoção de coliformes totais e termotolerantes foi bastante satisfatório, quando comparado aos obtidos por outros autores, que trataram efluentes eutrofizados. O sistema de tratamento pode ser utilizado como alternativa eficiente, simples e de baixo custo no tratamento de efluentes domésticos e residuais.

Em meio natural a planta atua como agente fitodepurador chegando a zerar as populações de coliformes, entretanto, mesmo a planta apresentando um decaimento significativo médio de 3,34895 log NMP/100 mL das populações de coliformes em meio artificial, para constatar essa hipótese e apresentar um melhor desempenho na remoção dos referidos parâmetros, é necessário um aumento no tempo do experimento para confirmar total diminuição do nível de contaminação.

\section{REFERÊNCIAS BIBLIOGRÁFICAS}

1. AD, Amaral MCE. Pontederiaceae. In: Wanderley MGL, Shepherd GJ, Melhem TS, et al., editores. Flora Fanerogâmica do Estado de São Paulo. vol. 4. São Paulo: Rima; 2005. p. 325-330.

2. Oliveira Junior MJ. Uso de macrófitas da espécie Pistia stratiotes (alface d'água) como combustível sólido para fornalhas industriais, uma análise de viabilidade técnica e econômica. [dissertação]. São Paulo (SP): Escola de Economia de São Paulo; 2011. 56 p.

3. Souza JT, Haandel ACV, Lima EPC, Henrique IN. Utilização de wetland construído no pós-tratamento de esgotos domésticos pré-tratados em reator UASB. Eng Sanit Ambient. 2004;9(4):285-90. doi: 10.1590/S1413-41522004000400004

4. Gonçalves Júnior AC, Lindino CA, Rosa MF, Bariccatti R, Gomes GD. Remoção de metais pesados tóxicos cádmio, chumbo e cromo em biofertilizante suíno utilizando macrófita aquática (Eichornnia crassipes) como bioindicador. Acta Scientiarum Technology. 2008;30(1):9-14.

5. Pescod MB. Wastewater treatment and use in Agriculture. Rome (IT): FAO; 1992. $125 \mathrm{p}$.

6. Trabulsi LR, Alterthum F. Microbiologia. 5. ed. São Paulo: Atheneu; 2008. 760 p.

7. Silva N, Junqueira VCA, Silveira NFA, Taniwaki MH, Santos RFS, Gomes RAR. Manual de métodos de análise microbiológica de alimentos. 3. ed. São Paulo: Varela; 2007. 552 p.

8. Salati E. Utilização de sistemas de wetlands construídas para tratamento de águas. [dissertação]. São Carlos (SP): Programa de Pós-Graduação em Ciências da Engenharia Ambiental, Escola Estatual de São Carlos; 2000. 36 p.

9. Quege KE. Tratamento de esgoto sanitário pelo sistema zona de raízes utilizando plantas de bambu. [dissertação]. Gioânia (GO): Universidade Federal de Goiás (UFG), Escola de Engenharia Civil; 2011. 
10. Von Sperling M. Princípios do tratamento biológico de águas residuárias - Introdução à qualidade das águas e ao tratamento de esgotos. vol. 2. Minas Gerais: ABES; 2005. 452 p.

11. Kadlec RH, Knight RL. Treatment wetlands. Boca Raton (FL): Lewis Publishers; 1996. 893 p.

12. United States Environmental Protection Agency (USEPA). EPA/625/R-99/010: Manual for constructed wetlands treatment of municipal wastewaters. Cincinnati (OH): USEPA; 2000. 166 p.

13. Instituto de Economia Agrícola (IEA). Os números da citricultura. São Paulo: IEA; 1997. 28 p.

14. Sanches AL, Cervi AC, Pott VJ. Levantamento taxonômico de Pontederiaceae Kunth do pantanal, nos estados de Mato Grosso e Mato Grosso do Sul, Brasil. In: Anais do III Simpósio sobre Recursos Naturais e Sócio-econômicos do Pantanal; 27-30 nov 2000; Corumbá (MS).

15. Nascimento HCE, Andrade IM, Silva MFS, Matias LQ. Pontederiaceae do litoral piauiense, Brasil. Rodriguésia. 2013;64(3):625-34. doi: 10.1590/S2175-78602013000300013

16. Sousa DJL, Giulietti AM. Flora da Bahia: Pontederiaceae. Sitientibus. 2014;14:1-30. doi: $10.13102 / \mathrm{scb} 360$

17. Reflora. Herbário Virtual [Internet]. Rio de Janeiro: Instituto de Pesquisas Jardim Botânico do Rio de Janeiro; 2020 [acesso em 11 fev 2020]. Disponível em: http://reflora.jbrj.gov.br/reflora/herbarioVirtual/

18. Zacarkim CE, Gomes SD, Palacio SM, Welter RA. Avaliação de sistema wetland construído no póstratamento de efluentes de curtume. In: Anais do $24^{\circ}$ Congresso Brasileiro de Engenharia Sanitária e Ambiental; 2-7 set 2007; Belo Horizonte (MG).

19. Ayres M, Ayres Jr M, Ayres DL, Santos AAS. BioEstat 5.3 - Aplicações estatísticas nas áreas das Ciências Biomédicas. Belém (PA): Instituto Mamirauá; 2007. 364 p.

20. Almeida RA, Almeida NAM. Remoção de coliformes do esgoto por meio de espécies vegetais. Rev Eletrônica de Enfermagem. 2006;7(3):306-17. doi: 10.5216/ree.v7i3.902

21. Pinto FR, Henares MNP, Cruz C, Amaral LA. Remoção de Escherichia coli de efluentes de carcinicultura por macrófitas aquáticas flutuantes. Ars Veterinaria. 2009;25(3):147-50. doi: 10.15361/2175-0106.2009v25n3p147-150

22. Borba J, Leste AN, Xavier EG, Silva FB, Melo AM. Tratamento de efluentes industriais através da utilização de plantas na despoluição da água, associado à decantação e filtração lenta. Científic@ Multidisciplinary J. 2018;5(2):132-6. doi: 10.29247/2358-260X.2018v5i2.p132-137

23. Brasil. Ministério do Meio Ambiente, Conselho Nacional do Meio Ambiente. Resolução no 357, de 18 de março de 2005. Dispõe sobre a classificação dos corpos de água e diretrizes ambientais para o seu enquadramento, bem como estabelece as condições e padrões de lançamento de efluentes, e dá outras providências. Diário Oficial da União. 18 mar 2005;53(Seção 1):58-63. Disponível em: http://www.siam.mg.gov.br/sla/download.pdf?idNorma $=2747$

24. Cunha CAG. Análise de eficiência de um sistema combinado de alagados construídos na melhoria da qualidade das águas [tese]. São Carlos (SP): Universidade de São Paulo; 2006. 157 p.

25. Lopes CMF. Estudo de uma área alagada do rio Atibaia visando à elaboração de proposta de manejo para melhoria da qualidade da água no reservatório de Salto Grande (Americana, SP) [tese]. São Carlos (SP): Universidade de São Paulo; 2000. 145 f.

26. Marques DM. Terras úmidas construídas de fluxo subsuperficial. In: Campos JR, coordenador. Tratamento de esgotos sanitários por processo anaeróbio e disposição controlada no solo. Rio de Janeiro: ABES; 1999. p. 409-435.

27. Ceballos BSO, Meira CMBS, Sousa JT, Oliveira H, Guimarães AO, Konig A. Desempenho de um leito cultivado na melhoria da qualidade de um córrego poluído destinado à irrigação. In: Anais do $27^{\circ}$ Congresso Interamericano de Ingenieria Sanitaria y Ambiental. Porto Alegre (RS): ABES; 2000.

28. Meira CMBS, Ceballos BSO, Sousa JT, Konig A. Wetlands vegetados no polimento de águas superficiais poluídas: primeiros resultados. In: Anais do $21^{\circ}$ Congresso Brasileiro de Engenharia Sanitária e Ambiental. João Pessoa (PB): ABES; 2001.

29. Diniz CR, Ceballos BSO, Barbosa JEL, Konig A. Uso de macrófitas aquáticas como solução ecológica para melhoria da qualidade de água. Rev Bras Eng Agríc Amb. 2005;9(suppl 1):226-30. doi: 10.1590/1807-1929/agriambi.v9nsupp226-230

30. United States Environmental Protection Agency (USEPA). Environmental Management Systems (EMS) [Internet]; 2008 [acesso em 27 abr 2020]. Disponível em: http://www.epa.gov

31. Esteves FA, Camargo AFM. Sobre o papel das macrófitas aquáticas na estocagem e ciclagem de nutrientes. Acta Limnol Bras. 1986;1:273-98.

32. Souza LEL, Bernardes RS. Avaliação do desempenho de um RAFA no tratamento de esgotos domésticos, com pós-tratamento através de leitos cultivados. In: Anais do Simpósio Italo-Brasiliano de Ingeniería Sanitaria-Ambientale. v. 1, n. 9. Gramado (RS): ABES; 1996.

33. Souza JT, Haandel ACV, Cosentino PR, Guimarães AVA. Pós-tratamento de efluente de reator UASB utilizando sistemas "wetlands". Rev Bras Eng Agríc Amb. 2000;4(1):87-91. doi: 10.1590/S141543662000000100016 
34. Sezerino P, Philippi LS. Utilização de um sistema experimental por meio de "Wetland" construído no tratamento de esgotos domésticos pós tanque séptico. In: IX Simpósio Luso-Brasileiro de Engenharia Sanitária e Ambiental; 2000; Porto Seguro (BA). Rio de Janeiro (RJ): ABES; 2000.

35. Branco SM, Bernardes RS. Culturas hidropônicas como forma de remoção e reciclagem de nutrientes minerais dos efluentes de sistemas de tratamento de esgotos. Rev DAE. 1983;134:113-5.

36. Nath KJ, Ramarao SV, Nair S, Gilman RH, Mullick D. Low cost wastewater treatment with water hyacinth. In: Thyagarajan G, editor. Proceedings International Conference on Water Hyacinth; Hydrabad, India. Nairobi (KE): United Nations Environment Programme; 1984. p. 655-663.

37. Reddy KR, Debusk WF. Growth characteristics of aquatic macrophytes cultured in nutrient enriched water: water hyacinth, water lettuce and pennywort. Economic Bot. 1984;38(2):229-39. doi: 10.1007/BF02858838

38. Prasad BGS, Madhavakrishna W, Nayudamma Y. Utilization of water hyacinth in the treatment and disposal of tannery wastewater. In: Thyagarajan G, editor. Proceedings International Conference on Water Hyacinth; Hydrabad, India. Nairobi (KE): United Nations Environment Programme; 1984. p. 647-654.

39. Polprasert C, Kessomboon S, Kanjanaprapin W. Pig wastewater treatment in water hyacinth ponds. Water Sci Technol. 1992;26(9-11):2381-4. doi: 10.2166/wst.1992.0742

40. Mandi L. Marrakesh wastewater purification experiment using vascular aquatic plants Eichhornia crassipes and Lemna gibba. Water Sci Technol. 1994;29(4):283-7. doi: 10.2166/wst.1994.0210

41. Casabianca ML. Large-scale production of Eichhornia crassipes on paper industry effluent. Bioresour Technol. 1995;54(1):35-8. doi: 10.1016/0960-8524(95)00111-5

42. Costa RHR, Bavaresco ASL, Medri W, Philippi LS. Tertiary treatment of piggery wastes in water hyacinth ponds. Water Sci Technol. 2000;42(10-11):211-4. doi: 10.2166/wst.2000.0645

43. Sooknah RD, Wilkie AC. Nutrient removal by floating aquatic macrophytes cultured in anaerobically digested flushed dairy manure wastewater. Ecol Eng. 2004;22(1):27-42. doi: 10.1016/j.ecoleng.2004.01.004

44. Guimarães FP. Potencial de macrófitas para remoção de arsênio e atrazine em solução aquosa. [dissertação]. Viçosa (MG): Universidade Federal de Viçosa; 2006. 87 p.

45. Perazza MC, Pereira DN, Martins MT. O aguapé: meios de controle e possibilidades de utilização. Rev DAE. 1985;125:18-24.

46. Bianchini Junior I, Cunha-Santino MB, Milan JAM, Rodrigues CJ, Dias JHP. Growth of Hydrilla verticillata (L.f.) Royle under controlled conditions. Hydrobiologia, 2010;644:301-12. doi: 10.1007/s10750-010-0191-1

47. Hamaamin YA, Adhikari U, Nejadhashemi AP, Harrigan T, Reinhold DM. Modeling Escherichia coli removal in constructed wetlands under pulse loading. Water Res. 2014;50:441-54. doi: 10.1016/j.watres.2013.10.052

48. Mclain JET, Williams CF. Seasonal variation in accurate identification of Escherichia coli within a constructed wetland receiving tertiary-treated municipal effluent. Water Res. 2008;42(15):4041-8. doi: 10.1016/j.watres.2008.06.003

49. Henry-Silva GG, Camargo AFM, Pezzato MM. Effect of nutriente concentration on the growth of aquatic macrophytes Eichhornia crassipes, Pistia stratiotes and Salvinia molesta. In: Proceedings of the 11th EWRS International Symposium on Aquatic Weeds, Moliets et Maa, France. European Weed Research Society, Doorwerth. The Netherlands; 2002. p. 147-50.

50. Silvestri PP. Aguapé - Bom ou Ruim, Mocinho ou Bandido. Paulo Pisati Silvestri [Internet]; 2010 [acesso em 27 abr 2020]. Disponível em: http://pps07.com/Aguape.html

51. Sipaúba-Tavares LH. Utilização de biofiltros em sistema de cultivo de peixes. Informe Agropecuário. 2000;(21):38-43. 